\title{
What can sown wildflower strips contribute to butterfly conservation?: an example from a Swiss lowland agricultural landscape
}

\author{
Christine Haaland • Louis-Félix Bersier
}

\begin{abstract}
The objective of this study was to compare butterfly abundances and diversity between wildflower strips and extensively used meadows to identify which butterfly species can be supported by establishing wildflower strips. Butterflies were recorded along transects during one season in twenty-five sown wildflower strips and eleven extensively used meadows in a Swiss lowland agricultural landscape (600 ha). In total 1,669 butterflies of 25 species were observed ( 25 in the strips, 18 in meadows). This can be related to 38 species recorded in the region (lowland part of Kanton Fribourg) within the Swiss Biodiversity Monitoring Programme. In wildflower strips the number of butterflies per transect meter was significantly higher than in the meadows, but there was no significant difference in species richness. Butterfly communities, though, were quite different between the two habitat types. Habitat type, abundances of flowering plants and presence of forest within $50 \mathrm{~m}$ were identified as factors influencing butterfly species richness. Butterfly abundances were affected by habitat type and abundance of flowering plants. In wildflower strips, $65 \%$ of all flower visits by butterflies were observed on Origanum. It can be concluded that sown wildflower strips can support a substantial part of a regions species pool. This is mostly true for common species, but can apply to rare species when, for example, larval food plant requirements are met.
\end{abstract}

C. Haaland $(\bowtie)$

Department of Landscape Management, Design and

Construction, Swedish University of Agricultural Sciences,

Box 66, 23053 Alnarp, Sweden

e-mail: christine.haaland@1tj.slu.se

L.-F. Bersier

Department of Biology, Unit Ecology and Evolution, University of Fribourg, Chemin du Musée 10, 1700 Fribourg, Switzerland
Keywords Agri-environmental schemes - Flower visits · Grassland management · Larval food plant · Larval habitat $\cdot$ Regional species pool $\cdot$ Switzerland

\section{Introduction}

The intensification of agriculture has caused severe species losses and declines due to habitat loss, habitat fragmentation and habitat degradation. The decline of butterflies in agricultural landscapes has been particularly well documented (e.g. Van Dyck et al. 2009; Van Swaay et al. 2006, 2009). To counteract the negative effects of intensive agricultural use and to maintain extensive management forms, agri-environmental schemes have been introduced within the EU and other European countries several decades ago. Sown wildflower strips are an agri-environmental measure intended to benefit in particular insects, not least because of their importance as pollinators, in pest control and their crucial role in food webs (Marshall et al. 2006; Pfiffner and Wyss 2004; Pywell et al. 2006; Woodcock et al. 2005). The diminishing of nectar resources, for example, has been acknowledged as a cause for decline of bumblebees (Carvell et al. 2006). Wildflower strips have been, or are planned to be, established in several European countries (e.g. Carvell et al. 2007; Haaland et al. 2010; Pywell et al. 2007). In Switzerland they were introduced as agri-environmental scheme in 1993. Schemes for wildflower strips vary between regions and countries regarding their seed mixture, length of funding and management. Seed mixtures can comprise few or up to 30 plant species, some include grasses, some only flowering herbs. The objectives can range from providing nectar resources for certain pollinators to enhancing overall biodiversity in intensively agricultural areas by providing larval, adult 
and overwintering habitats for a wider range of species (Nentwig 2000).

The benefit of wildflower strips on insect diversity has been studied especially in countries where wildflower strips have been established for a longer period of time, as in the UK and Switzerland (e.g. Aviron et al. 2007a; Carvell et al. 2007; Pfiffner and Wyss 2004; Pywell et al. 2005; Woodcock et al. 2008). The results of these studies have so far shown that sown wildflower strips have often higher insect diversity or abundances than other types of subsidised field margins, as natural regeneration or grass margins (e.g. Carvell et al. 2004; Meek et al. 2002; Pywell et al. 2005). Factors identified as influencing insect diversity or abundances are, for example, abundance of flowering plants (Carvell et al. 2004; Feber et al. 1996; Heard et al. 2007; Kohler et al. 2008), management (e.g. Feber et al. 1996; Woodcock et al. 2008), age of the strips (e.g. Carvell et al. 2007; Frank and Künzle 2006) and landscape factors such as patch size, connectivity, and landscape context (e.g. Aviron et al. 2007a, 2010; Heard et al. 2007). Butterflies have been shown to occur in higher abundances in strips containing wildflowers than other strips with grasses only, or with natural regeneration (Feber et al. 1996; Haaland and Gyllin 2010; Meek et al. 2002; Pywell et al. 2007). Aviron et al. (2007a) found in a study area in Switzerland higher diversity and abundance of butterflies in wildflower strips than in conventional grasslands or wheat fields. Jacot et al. (2007) observed in another Swiss study butterfly species and individuals numbers in wildflower strips that are comparable to biodiversity hotspots. The authors also noted that wildflower strips with grasses had higher butterfly species richness and abundances than wildflower strips without grasses.

The objective of this study was firstly to investigate butterfly species richness and abundances in Swiss sown wildflower strips in comparison to extensively used meadows, a habitat that was assumed to be one of the species richest habitats (regarding butterflies) in lowland agricultural landscapes. It was thought that the meadows could act as a source for individuals in wildflower strips, which are regularly ploughed up after a maximum of 7 years and newly established at the same place or somewhere else. Thus, a hypothesis was that wildflower strips would contain a subset of butterfly species presented in extensively used meadows. Number of flowering plant species, flower abundance, habitat area and the presence/absence of forest in $50 \mathrm{~m}$ buffers were analysed as possible factors influencing species richness and abundances. Secondly, the observed species richness was to be compared with the regional species pool to evaluate the proportion of butterfly species found in the wildflower strips in the study area. Finally, it was aimed to identify factors influencing butterfly diversity and abundances in the strips and in the meadows.

\section{Methods}

Study area

The study area was situated in the Western part of Switzerland in the municipality of Bösingen, Kanton Fribourg (Fig. 1). It comprised a size of about 600 ha and the highest point lies $650 \mathrm{~m}$ above sea level. The area belongs to the Schweizer Mittelland which covers the Western lowlands of Switzerland between the Jura and the Alps. The landscape was characterized by rather small-scale agriculture with small fields, some woodlands and spread settlements. The agricultural land was dominated by arable with cereal, corn and potato production, but there was also considerable amount of grassland (ca 20\%, estimated from orthophotographs), most of it was intensively used. Areas with agri-environmental schemes (grasslands, orchards, sown wildflower strips, grass strips along woodlands and watercourses and hedges) covered about $15 \%$ of the study area (administrative map on agri-environmental payments of the municipality Bösingen). Areas with this type of agrienvironmental scheme are called ecological compensation areas in Switzerland. All together, the study area represented a rather less intensively used part of the Mittelland with a large amount of ecological compensation area.

The sown wildflower strips were created using with a standard seed mixture often applied in Switzerland containing 24 different plant species (species list in Appendix A). None of the wildflower strips showed signs of mowing during the study period. The age of the strips varied between one and 7 years. Within the study area all sown wildflower strips were investigated. Among meadows, a selection was made. Only meadows that had the least intensive management, according to the agricultural schemes, were selected. These meadows were cut at least twice a year, but due to regulation not before the middle of June. During the study 25 sown wildflower strips and 11 meadows were investigated. The mean size of the wildflower strips was 0.41 ha $(\min 0.15$, $\max 1.16)$ and of the meadows 0.76 ha $(\min 0.21, \max 1.64)$; the difference in means is significantly different ( $t$-test: $t$-value: $-3.08, d f 34$, $P=0.004)$. Of the 11 meadows, 9 had a polygon shape and 2 were strips. The wildflower strips had in 15 cases a strip shape and in 10 cases a polygon shape.

\section{Butterfly recording}

Butterflies were recorded along transects five times between May and September 2008, once each month. Transects were placed in the middle of the strips or patches and were walked along the whole strip or patch. Butterflies were recorded three meters each side of the transect line. The width of total six meters for butterflies was chosen 
Fig. 1 Map with location of the study area in the municipality of Bösingen, Kanton Fribourg, Switzerland

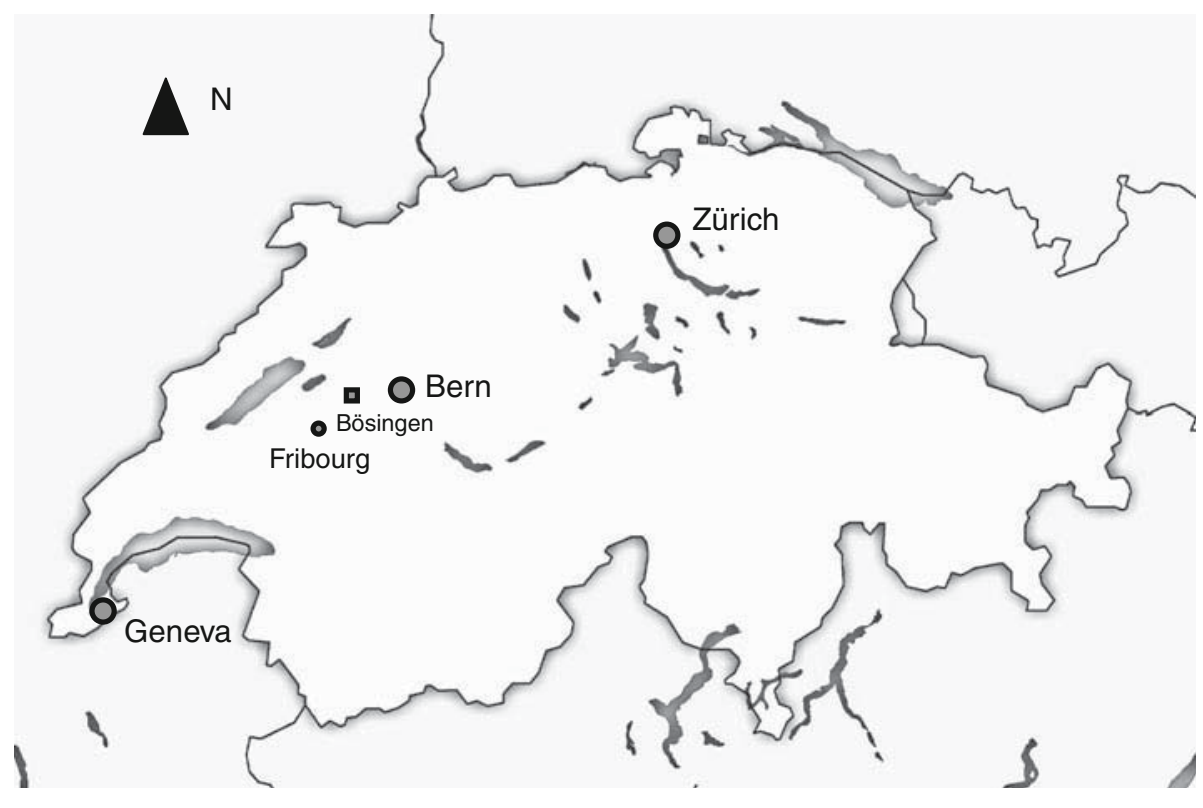

since it corresponded to the width of several wildflower strips. Usually butterflies were identified to species level, but Colias hyale and Colias alfacariensis were not distinguished and also not the two Thymelicus species T. lineola and $T$. sylvestris. Recordings were carried out between 10 am and $5 \mathrm{pm}$ and only in good weather conditions (Pollard and Yates 1993). When butterflies were observed using flowers, the visited species were recorded. To account for the differences in transect lengths, we expressed species richness and abundance as density per sampled meter (note that the relationship between transect length and species richness was best described by a linear model).

\section{Regional butterfly species pool}

The butterfly species lists obtained from the recordings for both habitat types were compared with monitoring results for the lowland part of Kanton Fribourg of the Swiss Biodiversity Monitoring Programme for butterflies. The comparison was carried out to obtain information on how many butterfly species could be potentially expected in the study area and for which butterfly species larval food plants were available or not in the two investigated habitats in the study area. Further information on the methodology on recording within the monitoring programme can be gained from the Koordinationsstelle Biodiversitäts-Monitoring Schweiz (2008). Larval food plants for butterflies were obtained from Schweizerischer Bund für Naturschutz (1994).

Plant recording including larval food plants

In each transect $(6 \mathrm{~m}$ width) all flowering plants were recorded during the five sampling sessions and classified into five groups according to their flower abundance. Classes ranged from 1 to 5 , whereby

$1=$ very rare (one flowering individual)

$2=$ rare (few flowering individuals)

$3=$ spread (flowering individuals frequently spread)

4 = abundant (many flowering individuals, but not dominating)

$5=$ very abundant (very many flowering individuals, dominating).

Not all plants could be identified to species level; in several cases plants were identified only to genus. The total number of flowering species per site and a flower abundance index was calculated. The flower index is the sum of all flower abundance classes per investigated habitat patch of Rumex spp., Urtica dioica, Viola spp. and grasses (Poaceae) were also recorded independently of their flowering status. These taxa are larval food plants and might otherwise be missed while recording flowering plants.

Spatial variables

The investigated wildflower strips and meadows were digitized in the geographical information system (GIS) ArcGIS (Esri 2006) using an ortophotograph from 2006. The spatial variables were transect length, area of wildflower strips and of meadows, and presence/absence of forest in a $50 \mathrm{~m}$ buffer around the transect.

Analysis

Statistical analysis were carried out in R (R Development Core Team 2009) and Statistica (StatSoft 1997). (wildflower strip/meadow). At the first visit, the abundance 
A stepwise multiple linear regression was applied to analyse factors influencing butterfly abundance and species richness in sown wildflower strips and meadows. Additionally, a correspondence analysis (CA) was carried out with the R package "vegan" (Oksanen et al. 2010) to analyse species composition of the study sites and factors influencing species composition.

\section{Results}

Butterfly abundance and diversity in wildflower strips and meadows

In total the transect length was $6.7 \mathrm{~km}$ of which $4.9 \mathrm{~km}$ $(73 \%)$ were in wildflower strips and $1.8 \mathrm{~km}(27 \%)$ in meadows. The mean transect length in wildflower strips was $200 \mathrm{~m}(\min 70 \mathrm{~m}, \max 450 \mathrm{~m})$ and did not differ significantly from that in meadows (mean $165 \mathrm{~m}$, min $85 \mathrm{~m}$, max $310 \mathrm{~m}$; $t$-test : $t$-value: $0.94, d f 34, P=0.355)$. Altogether 1,669 butterflies of 25 species were observed (Appendix B). By far the most butterflies $(88 \%, n=1,464)$ were recorded in wildflower strips. The number of butterflies per transect meter was significantly higher in wildflower strips than in the meadows ( $t$-test: $t$-value $3.47, d f 34, P=0.0014$, Fig. 2a). All 25 species were recorded in the wildflower strips and 18 species in the meadows. The difference in species richness per transect meters was marginally significant ( $t$-test: $t$-value: $1.97, d f 34, P=0.057$, Fig. $2 b$ ). Figure 3 shows the distribution of species within both types of habitats. The first ordination axis explains $16.3 \%$ of the variation in butterfly abundances within the 36 sites, the second $13.1 \%$. It is apparent that the wildflower strip and meadow sites naturally segregate according to species

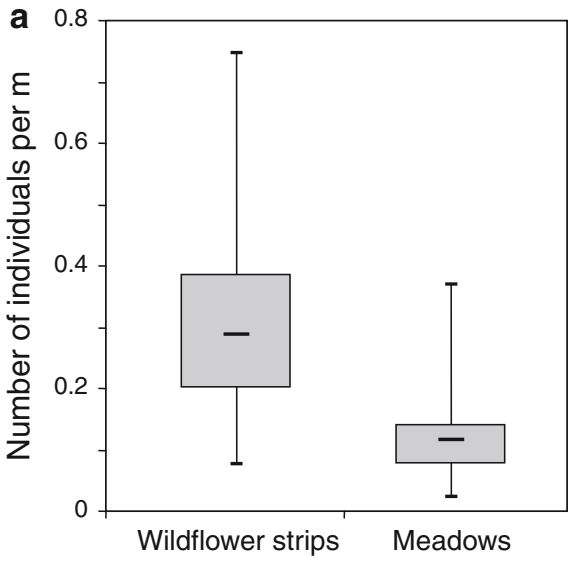

Fig. 2 a Box plot (minimum, 25th percentile, median, 75th percentile, maximum) of number of butterflies per meter in wildflower strips and meadows ( $t$-test: $t$-value: $3.47, d f 34, P=0.0014$ ). Total number of butterflies recorded in wildflower strips was 1,464 and 205 in composition. Species that were more often observed in the meadows than expected (taking into account the differences in transect length in the two studied habitats) were the mazarine blue (Cyaniris semiargus), common blue (Polyommatus icarus), pale clouded yellow (Colias hyale/alfacariensis) marbled white (Melanargia galathea) and the small heath (Coenonympha pamphilus). A species that exclusively occurred in the wildflower strips was the mallow skipper (Carcharodus alceae). The mallow skipper was listed as "critically endangered" in the Swiss red data book (Gonseth 1994), but is now one of the most abundant butterfly species in wildflower strips in the study area. This species was absent in the investigated meadows, where its food plants (Alcea rosea, Malva alcea, M. moschata, M. neglecta, M. sylvestris, Ebert 1993) rarely occurred.

Flowering plant species

Eighty-five species and 11 genera of flowering plants were identified. The mean number of flowering plant taxa was 27.7 ( \pm 7.9 s.d.) on transects in wildflower strips, a figure significantly larger than the 17.9 ( \pm 5.5 s.d.; $t$-test: $t$-value: 3.72, $d f 34, P<0.001)$ in meadows. Between 6 and 21 of the 24 sown species were recorded in flower in the wildflower strips. The species sown in the wildflower strips did not usually occur, or occurred in much lower frequencies, in the meadows, the only exception was Leucanthemum vulgare. In the meadows, several species were much more abundant than in the wildflower strips, these were Trifolium spp. (mostly $T$. pratense and $T$. repens, but also T. campestre), Ranunculus spp., Plantago lanceolata, Knautia arvensis and Leontodon autumnalis. Even though grasses were not sown in the wildflower strips, grasses were very abundant in most strips due to succession.

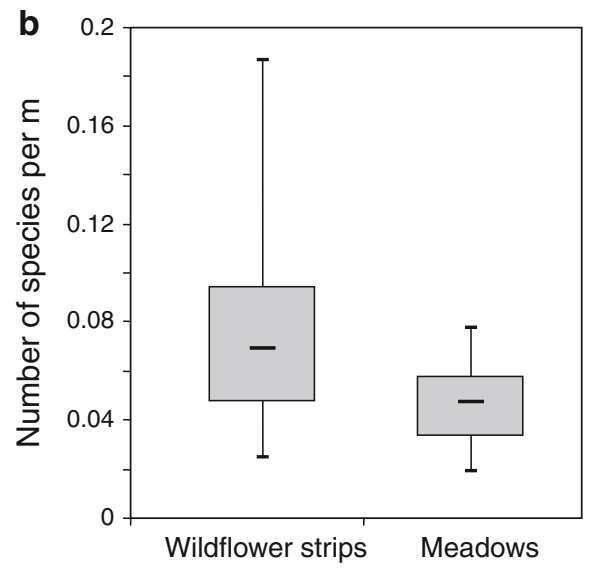

meadows, b Box plot of butterfly species richness per meter in wildflower strips and meadows ( $t$-test: $t$-value 1.97 , $d f 34, P=0.057$ ). Total number of butterfly species recorded in wildflower strips was 25 and 18 in meadows 


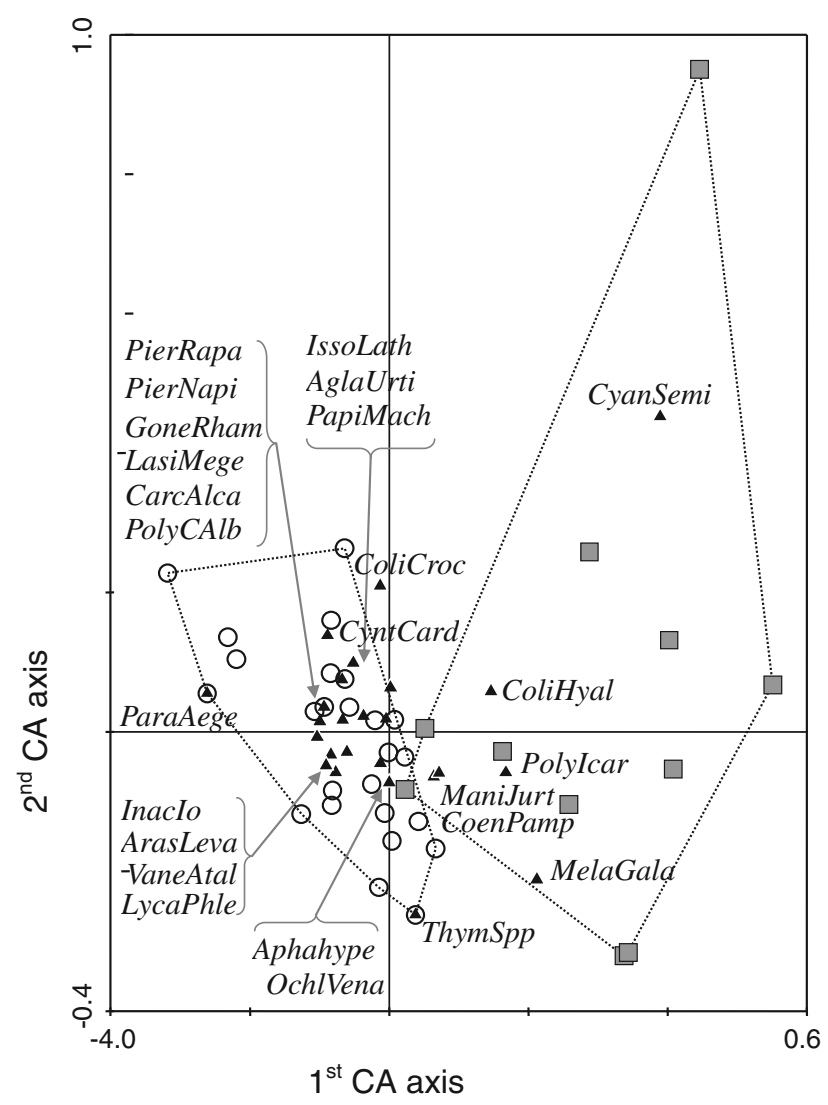

Fig. 3 Results of correspondence analysis. Black triangles: butterfly species (four-first letters of genus and of species; see Appendix B for complete names); circles: wildflower strips, grey squares: extensively used meadows; dotted lines enclose the corresponding sites

Factors influencing butterfly species richness and abundance

The results of the multiple linear regressions (stepwise forward) showed that the explanatory variables can explain between 75 and $66 \%$ of the variation in butterfly abundance and species richness respectively (Table 1). Significant factors related with butterfly abundances were habitat type (meadows having less species than wildflower strips) and flowering plant species richness. There was also a positive effect of transect length on abundances. Butterfly species richness was influenced significantly by the factor habitat type (same trend as above) and flower abundance (expressed as flower index). Additionally, the presence of forest in the $50 \mathrm{~m}$ buffer positively affected butterfly species richness. There is a linear relationship between the factors flowering plant species and flower index $\left(R^{2}=0.78\right)$.

Flower visits

In wildflower strips, $42 \% \quad(n=609)$ of all butterfly recordings concerned individuals perched on a flower, whereas in meadows only $19 \%(n=39)$ of all butterfly observations were flower visits. In wildflower strips $65 \%$ of all flower visits occurred on Origanum vulgare, $11 \%$ on Centaurea jacea and 9\% on Epilobium ciliatum (Fig. 4).

Comparison with regional species pool and availability of larval food plants

The Swiss Biodiversity Monitoring Programme of the lowland part of Kanton Fribourg, which includes the study region, comprised 4101 butterfly observations of 38 species between 2003 and 2007. Of these 38 species two-third $(n=25)$ were recorded in the wild flower strips of the study area. Amongst the species not observed in the study area in Bösingen were the five rarest species (with only 1 individual observed during the monitoring: Apatura ilia, Red list (RL) category according to Gonseth (1994) 2, endangered; Cupido minimus, RL 3, vulnerable; Leptidea

Table 1 Results of the multiple linear regression (stepwise forward); explanatory variables entered in the analysis were: habitat_type $(\mathrm{M}=$ meadow $)$, transect length, area, number of flowering species

(flower_species), flower_index (sum of all abundance classes of all flowering species over the whole season), presence/absence of forest within a $50 \mathrm{~m}$ buffer (forest_50 m)

\begin{tabular}{|c|c|c|c|c|c|}
\hline Dependent variable & Independent variable & Beta & Multiple $R$-square & $F$-to entr & $P$-level \\
\hline \multirow[t]{5}{*}{ Butterfly abundance $(\log )$} & Flower_species & 0.461 & 0.60 & 50.5 & $<0.001 * * *$ \\
\hline & Transect length & 0.275 & 0.65 & 5.3 & $0.027 *$ \\
\hline & Habitat_type (M) & -0.387 & 0.71 & 5.8 & $0.022 *$ \\
\hline & forest_50 m & 0.152 & 0.74 & 3.8 & 0.060 \\
\hline & Area & 0.140 & 0.87 & 0.75 & 0.222 \\
\hline \multicolumn{6}{|c|}{$R^{2}=0.75$, Adjusted $R^{2}=0.71 ; F(5,30)=18.17, P<0.001$, Std. Error of estimate: 0.198} \\
\hline \multirow[t]{4}{*}{ Butterfly species richness (log) } & Flower_index & 0.435 & 0.47 & 29.8 & $<0.001 * * *$ \\
\hline & Habitat type & -0.495 & 0.55 & 6.1 & $0.018 *$ \\
\hline & Forest_50m & 0.237 & 0.63 & 6.7 & $0.014 *$ \\
\hline & Area & 0.211 & 0.66 & 2.9 & 0.097 \\
\hline
\end{tabular}

$R^{2}=0.66$, Adjusted $R^{2}=0.62 ; F(4,31)=15.08 P<0.001$ Std. Error of estimate: 0.092 


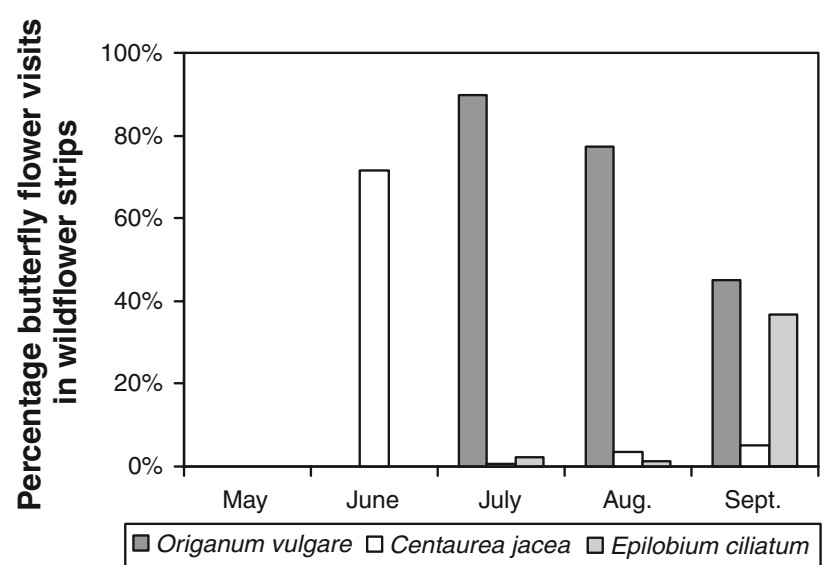

Fig. 4 Change of flower visits in wildflower strips during the season with regard to the three most visited flowering plant species (number of butterfly visits $=609$ )

sinapis, Melitaea athalia RL 3; Nymphalis antiopa, RL 3), further two species with woody plant species as larval food plant (Celastrina argiolus, Limenitis camilla), three fritillary species (Argynnis paphia; Brenthis daphne, RL 2; Clossiana dia, RL 2) and Lycaena tityrus. It can be noted that in particular fritillaries were not well represented within the wildflower strips and in the meadows.

A comparison of presence and absence of butterflies in the study area (in relation to the regional species pool) with the larval food plant availability in the studied sites (based only on absence/presence data for all transects combined) is shown in Table 2. For $67 \%$ of the 33 species recorded

Table 2 Presence and absence of larval food plant and butterfly species in the two studied habitats in the study area as percentage of total number of species recorded in the lowland part of Kanton of Fribourg (Swiss Biodiversity Monitoring Programme, 2003-2007)

Percentage species of total number of species recorded in Kanton Fribourg (total number of species $=33^{\mathrm{a}}$ )

\begin{tabular}{ll}
\hline $\begin{array}{l}\text { Sown wildflower } \\
\text { strips }(n=25) \\
(\%)\end{array}$ & $\begin{array}{l}\text { Extensively managed } \\
\text { meadows }(n=11) \\
(\%)\end{array}$ \\
\hline 67 & 45 \\
21 & 30 \\
6 & 9 \\
6 & 15
\end{tabular}

LFP larval food plant; $B$ adult butterfly. Butterfly species with woody species as larval food plant (the 5 species Apatura ilia, Celastrina argiolus, Gonepteryx rhamni, Limenitis camilla, Nymphalis antiopa) have been excluded from the analysis since young trees and trees seedlings were not recorded as potential larval food plant

${ }^{a}$ Four species are pooled into two groups (Colias hyale and C. alfacariensis; Thymelicus lineola and T. sylvestris which were not separately recorded) within the monitoring programme (excluding species whose larvae feed on woody plants) the adult butterfly and the larval food plant were observed along transects in wildflower strips of the study area. For $21 \%$ the larval food plant was present in the wildflower strips, but the butterfly was not observed. These were species, which either are regionally rare, have different habitat requirements than open agriculture landscapes and/or a larval food plant that occurred in very low frequencies in the wildflower strips. Both the larval food plant and the butterfly were not found for $6 \%$ of the 33 species (mostly species where larvae feed on woody species) and in a further $6 \%$ the butterfly species was observed, but not the larval food plant.

\section{Discussion}

Three major conclusions can be drawn. Firstly, a considerable proportion $(66 \%)$ of butterflies present in the regional species pool were found in the wildflower strips. This has to be evaluated from the background that the number of butterfly species recorded within the Swiss monitoring programme in Kanton Fribourg is small compared to the total butterfly diversity in Switzerland (nearly 200 species). It has been noted that wildflower strips largely support common species (e.g. for bumblebees Pywell et al. 2005, for butterflies Aviron et al. 2010). It has also been pointed out that agri-envrinmental schemes in general often tend to support butterfly species of the wider-countryside (Settele et al. 2009). This applies also to a certain degree in this study. It is mostly widespread and common species that were found in the wildflower strips, but this is also true for the extensively managed meadows. Of seven red list species recorded within the monitoring scheme in Kanton Fribourg, only one species, the mallow skipper, was recorded within wildflower strips in the study area. However, even widespread and common butterfly species are in decline in landscapes with intensive use (Van Dyck et al. 2009) and wildflower strips are likely to be a measure to stabilise or even enhance the abundances of these species. Fritillaries are in decline in many European countries; they do not profit from the wildflower strips, at least not in the study area, probably because specific habitat requirements are not met.

Secondly, the butterfly communities in wildflower strips and the extensively used meadows were quite different, with higher abundances and species richness in the wildflower strips. It is important to remember that sampling intensity was different between the two habitat types, with almost three-fourths of the transect length being situated in the wildflower strips. Difference in total species richness are therefore not directly comparable. However, species richness per meter showed a close to significant differences 
$(P=0.057)$ between extensively used meadows and wildflower strips. With higher sampling efforts in the meadows differences might have become more visible. Also, the number of butterflies (per transect meter) was 2.5 times higher in the wildflower strips than in the meadows.

Species communities in the extensively used meadows are characterized by the presence of butterflies with grasses as larval food plant (Melanargia galathea, Coenonympha pamphilus, Maniola jurtina) and the two blues Polyommatus icarus and Cyaniris semiargus. The number of certain blues could probably be enhanced in wildflower strips by including certain Fabaceae (other than Onobrychis) in the seed mixture. From the result of the correspondence analysis (Fig. 3), it is clear that the hypothesis that wildflower strips contain a subset of species occurring in the meadows was not confirmed. In such a case, the wildflower strip sites would have been included inside the envelope (dotted line) of the meadow sites.

Thirdly, sown wildflower strips were used as larval habitat for several species. Butterfly larvae were not specifically investigated during this study, but several species, including the mallow skipper and the swallowtail, were observed using the larval hostplants present. The case of the mallow skipper shows that the provision of the larval food plant (in addition to adult food resources) can increase abundances considerably (see Appendix B, Wermeille and Carron 2005). The mallow skipper would probably not have been judged as a species with high dispersal ability, but the current density of wildflower strips seems to be sufficient to allow increases in abundances. Larvae of the swallowtail are very visible and were observed in wildflower strips on parsnip (Pastinaca sativa) and wild carrot (Daucus carota). It is thus very likely that the wildflower strips are beneficial for swallowtails in the study area.

The use of wildflower strips as larval habitat has implications for the design of wildflower strips regarding composition of seed mixture and duration of agri-environmental scheme (time span between sowing and eventual removal). When choosing seed mixtures, inclusion of larval food plants should be carefully considered as they can have a major positive impact of butterfly species. It would thus not be sensible to design the seed mixtures based only on needs as adult food resources (Feber et al. 1996). Nonadult life stages seem less often considered when designing agri-environmental schemes. This has, for example, been pointed out by Lye et al. (2009) regarding nesting sites for bumblebees compared to the provision of adult food resources. It is of great importance to acknowledge that in cases where wildflower strips are used as larval habitat, a short time span between sowing and ploughing (often the same time span as the duration of the agri-environmental scheme) can be detrimental since eggs might be laid in high numbers in habitats that are ploughed in late autumn or early spring. Short schemes for wildflower strips-for one or 2 years-are not unusual in some countries. Nevertheless, 5 years should be a minimum and removal should be rotational, or staggered.

The density of wildflower strips was comparatively high in the study area and they were quite evenly distributed, both factors that result in relatively short distances between strips. The success of wildflower strips for butterfly conservation may thus be dependent to a certain extent on their spatial distribution. Aviron et al. (2010) demonstrated a linear increase in butterfly diversity with percent cover of wildflower strips in Swiss agricultural landscapes. The authors therefore emphasised the importance of density and connectivity of wildflower strips in a landscape for butterfly diversity. In our study area, this was reached with the help of the administrators of the agri-environmental schemes, who explicitly choose a network approach. This meant informing and advising all farmers in the area for establishment of ecological compensation areas (an approach probably comparable with the high level stewardship schemes in the UK). This approach has previously shown success regarding moth conservation (Merckx et al. 2009).

The study also showed that the extensively used meadows in the study area were less favourable for butterfly conservation. We believe that they were still too intensively used and/or that the land use prior to entering the agri-environmental scheme was too intensive to support large numbers of butterflies (see also Aviron et al. 2007b). The current regulation allows several sward cuts starting in the middle of June as well as limited fertilizer application. Such practices are not beneficial for many butterfly species (Aviron et al. 2007c). $30 \%$ of butterfly species recorded within the monitoring scheme have their larval food plant present in the meadows, but were not recorded there (Table 2); this may be an indication of a suboptimal management. Similar problems for butterfly species conservation caused by early mowing of grassland over large areas allowed by regulations in agri-environmental schemes have been pointed out before (Konvicka et al. 2008; Settele et al. 2009; Walter et al. 2007).

Acknowledgments We want to thank Jacques Studer and Christian Imesch from the Ökobüro in Fribourg for providing all information on ecological compensation areas in the study area including maps. We are also very thankful to Matthias Plattner, Hintermann \& Weber AG, Basel, for the provision of the butterfly data from the Swiss Biodiversity Monitoring Programme (BDM). All farmers are thanked for allowing access to their land. Two anonymous reviewers have contributed to improve the manuscript. $\mathrm{CH}$ was financed by the Swedish Research Council FORMAS and LFB by the Swiss National Science Foundation (3100A0-113843). 
Haaland C, Naisbit RE, Bersier, L-F (2010) Sown wildflower strips for insect conservation-a review. Insect Conserv Divers (in press). doi:10.1111/j.1752-4598.2010.00098.x

Heard MS, Carvell C, Carreck NL, Rothery P, Osborne J, Bourke AFG (2007) Landscape context not patch size determines bumble-bee density on flower mixtures sown for agri-environment schemes. Biol Lett 3:638-641

Jacot K, Eggenschwiler L, Junge X, Luka H, Bosshard A (2007) Improved field margins for a higher biodiversity in agricultural landscapes. Aspects Appl Biol 81:277-283

Kohler F, Verhulst J, van Klink R, Kleijn D (2008) At what spatial scale do high-quality habitats enhance the diversity of forbs and pollinators in intensively farmed landscapes? J Appl Ecol 45:753-762

Konvicka M, Benes J, Cizek O, Kopecek F, Konvicka O, Vitaz L (2008) How too much care kills species: Grassland reserves, agri-environmental schemes and extinction of Colias myrmidone (Lepidoptera : Pieridae) from its former stronghold. J Insect Conserv 12:519-525

Koordinationsstelle Biodiversitäts-Monitoring Schweiz (2008) Anleitung für die Feldarbeit zum Indikator «Z7-Tagfalter ». Bern, Bundesamt für Umwelt. http://www.biodiversitymonitoring. ch/pdfs/downloads/875\%20Anleitung\%20Z7-Tagf\%20v14.pdf

Lye G, Park K, Osborne J, Holland J, Goulson D (2009) Assessing the value of Rural Stewardship schemes for providing foraging resources and nesting habitat for bumblebee queens (Hymenoptera: Apidae). Biol Conserv 142:2023-2032

Marshall EJP, West TM, Kleijn D (2006) Impacts of an agrienvironment field margin prescription on the flora and fauna of arable farmland in different landscapes. Agr Ecosyst Environ 113:36-44

Meek WM, Loxton D, Sparks TH, Pywell R, Pickett H, Nowakowski $M$ (2002) The effect of arable filed margin composition on invertebrate biodiversity. Biol Conserv 106:259-271

Merckx T, Feber RE, Riordan P, Townsend MC, Bourn NAD, Parsons MS, Macdonald DW (2009) Optimizing the biodiversity gain from agri-environment schemes. Agr Ecosyst Environ 130:177-182

Nentwig W (ed) (2000) Streifenförmige ökologische Ausgleichsflächen in der Kulturlandschaft: Ackerkrautstreifen, Buntbrachen, Feldränder. Verlag Agrarökologie, Bern Hannover, p 293

Oksanen J, Blanchet FG, Kindt R, Legendre P, O'Hara RG, Simpson GL, Solymos P, Stevens MHH, Wagner H (2010) vegan: Community Ecology Package. R package version 1:17

Pfiffner L, Wyss E (2004) Use of sown wildflower strips to enhance natural enemies of agricultural pests. In: Gurr GM, Wratten SD, Altieri MA (eds) Ecological engineering for pest management: advances in habitat manipulation for arthropods. Collingwood Victoria, CSIRO Publishing, pp 165-186
Pollard E, Yates TJ (1993) Monitoring butterflies for ecology and conservation. Chapman \& Hall, London, UK

Pywell RF, Warman EA, Carvell C, Sparks TH, Dicks LV, Bennett D, Wright A, Critchley CNR, Sherwood A (2005) Providing foraging resources for bumblebees in intensively farmed landscapes. Biol Conserv 121:479-494

Pywell RF, Warman EA, Hulmes L, Hulmes S, Nuttall P, Sparks TH, Critchley CNR, Sherwood A (2006) Effectiveness of new agrienvironment schemes in providing foraging resources for bumblebees in intensively farmed landscapes. Biol Conserv 129:192-206

Pywell RF, Meek WM, Carvell C, Hulmes L, Nowakowski M (2007) The Buzz project: biodiversity enhancement on arable land under the new agri-environment schemes. Aspects Appl Biol 81:61-68

R Development Core Team (2009) R: A language and environment for statistical computing. R Foundation for Statistical Computing, Vienna, Austria. ISBN 3-900051-07-0, URL http://www.Rproject.org

Schweizerischer Bund für Naturschutz (ed) (1994) Tagfalter und ihre Lebensräume. Arten-Gefährdung-Schutz. 4. Auflage. Holliger, Egg/ZH, Switzerland

Settele J, Dover J, Dolek M, Konvicka M (2009) Butterflies of European ecosystems: impact of land use and options for conservation management. In: Settele J, Shreeve T, Konvicka M, Van Dyck H (eds) Ecology of butterflies in Europe. Cambridge University Press, Cambridge, pp 353-370

StatSoft (1997) Statistica 5.1 StatSoft, Tusla, USA

Van Dyck H, Van Strien AJ, Maes D, Van Swaay CAM (2009) Declines in common, widespread butterflies in a landscape under intense human use. Conserv Biol 23:957-965

Van Swaay CAM, Warren MS, Lois G (2006) Biotope use and trends of European butterflies. J Insect Conserv 10:189-209

Van Swaay CAM, Maes D, Warren MS (2009) Conservation status of European butterflies. In: Settele J, Shreeve T, Konvicka M, Van Dyck $\mathrm{H}$ (eds) Ecology of butterflies in Europe. Cambridge University Press, Cambridge, pp 322-338

Walter T, Schneider K, Gonseth Y (2007) Schnittzeitpunkt in Ökowiesen: Einfluss auf die Fauna. Agrarforschung 14:114-119

Wermeille E, Carron G (2005) Value of fallows for the Mallow Skipper (Carcharodus alceae) and some other butterfly species. Revue Suisse d'Agricul 37:175-182

Woodcock BA, Westbury DB, Potts SG, Harris SJ, Brown VK (2005) Establishing field margins to promote beetle conservation in arable farms. Agr Ecosyst Environ 107:255-266

Woodcock BA, Westbury DB, Tscheulin T, Harrison-Cripps J, Harris SJ, Ramsey AJ, Brown VK, Potts SG (2008) Effects of seed mixture and management on beetle assemblages of arable field margins. Agr Ecosyst Environ 125:246-254 